\title{
Barriers to Energy Efficiency - Focus on Transaction Costs
}

\author{
M. Valentová
}

\begin{abstract}
This paper assesses the main barriers that prevent economic energy efficiency potential from being realized. The main barriers discussed here include energy prices (and prices of technology), limited access to capital, lack of information, incorrect risk assessment (i.e. setting a discount rate), the principal-agent problem and transaction costs. Transaction costs are analyzed in greater detail, as they are one way or another related to all of the barriers mentioned here. Based on the analysis, there is a discussion of implications for effective policy making. These are specially needed for transaction costs, where the availability of empirical data is very limited.
\end{abstract}

Keywords: barriers to energy efficiency, transaction costs, energy efficiency gap, energy efficiency instruments.

\section{Introduction}

Energy demand has become a major political topic, both on a national level and on an international level. With increasing energy prices and steady depletion of classical fossil fuels, energy issues are likely to become even more important in future.

The benefits of increased energy efficiency (EE) are widely known. Apart from lower energy demand and lower energy costs as such, it can provide a better working environment, environmental benefits, or from the macroeconomic point of view, job creation and lower import dependence. Political targets have been set at EU level and at international level (the so called 20-20-20 target for 2020, or the Kyoto targets). Energy efficiency as a strategic goal is clearly mentioned in the State energy concept of the Czech Republic.

The economic potential for energy savings is not negligible; it is estimated to be around 20 to $30 \%$. However, this potential remains to a large extent unexploited. This is because of the barriers to energy efficiency.

The paper analyzes the main barriers to energy efficiency, specifically focusing on transaction $\operatorname{costs}^{1}$. On the basis of this analysis, the paper presents possible implications for effective policies to overcome them.

\section{Barriers to efficiency}

The main barriers to energy efficiency are ${ }^{2}$ energy prices (and technology prices), limited access to capital, lack of information, incorrect risk assessment (i.e. setting a discount rate), the principal-agent problem and transaction costs. It is important to keep in mind though that the analyzed barriers never stand alone. On the contrary, the barriers are usually all interconnected and they may even reinforce each other [1], which renders potential policy making even more complex.

\subsection{Energy prices and prices of the technology}

Energy prices affect the implementation of energy efficiency measures in various ways. One factor is the actual share of energy costs in total costs, while another factor is the development of energy prices.

Energy costs very often form (except in energy intensive industries) only a small proportion of the overall expenditures. Also, when making a decision about an investment, energy consumption is only one of many criteria for decision [2]. This may negatively impact the implementation of otherwise cost-effective efficiency measures.

The development of energy prices is another key determinant of adoption or non-adoption of efficiency measures. Basically, increasing energy prices will lead to the use of more efficient technologies [3].

By the same logic, one could induce that, conversely, low energy prices will lead to the use of inefficient technologies. This is however true only to certain extent. Birol and Keppler [3] call this a ratchet effect, meaning that some level of efficient technologies will remain in place even if energy prices fall (e.g. households will not tear down new insulation just because energy prices decreased).

However, at the same time, there will always be some level of rebound effect, which is the increase in demand for energy services (and eventually in energy) due to the de facto lower price of energy (because of efficiency measures) measured in terms of energy services or efficiency units. The level of the rebound effect cannot be conceptually determined (only empirically),

\footnotetext{
${ }^{1}$ The special interest in transaction costs is because they are in one way or another related to all of the other barriers (either stemming from the other barriers or including them).

${ }^{2}$ Not in order of relevance.
} 
but it will always be a fraction between zero and one. When the rebound effect is one, it means that all the costs saved through efficiency measures will be translated into higher demand for energy services. Current empirical studies show that the level of the rebound effect varies in most cases between $10 \%$ and $30 \%[4,5]$.

\section{$2.2 \quad$ Limited access to capital}

Another barrier that is usually mentioned in relation to energy efficiency measures is the often high upfront costs of energy efficiency investments ${ }^{3}$. The problem itself concerns potentially limited access to capital. There are two groups of actors that are particularly influenced by this barrier: small and medium size enterprises (SMEs) and lower income households.

Paradoxically, it is the latter group that could make the highest efficiency gains [6]. At the same time though, it is low income households that have very difficult access to capital and to credit (and are also more likely to be unable to repay the loan).

Another issue with households (irrespective of income levels) is that energy efficiency investments have to compete with many other investments that a household has to make [7]. Households in general tend to be averse toward risk and towards credit.

Like low income households, small and medium size enterprises tend to have worse access to credit (with less favorable conditions than bigger companies).

An important sector for energy efficiency measures, the public sector, is in general a trustworthy client for the banks, because the risk of non-repayment is relatively low. Therefore, public sector actors will not usually have problems with access to capital per se. The constraint is different here - very often the level of indebtedness will be limited by law [7], therefore even though the public authorities could obtain credit for energy efficiency investment, they will not be allowed to do so.

\subsection{Lack of information}

One of the major barriers to energy efficiency is the lack of information of potential investors (both households and organizations). Due to lack of information, the costs of energy saving measures are likely to exceed the benefits for individual users $[8]^{4}$.

As in previous section, lack of information tends to be more relevant to households and
$\mathrm{SMEs}^{5}$. E.g. households will usually only compare the investment costs, but not the operation costs $[1]$.

Some authors $[1,9]$ mention the problem of lack of billing information. Households and also most small and medium enterprises very often get information on energy consumption once a year, not split down into different end-uses. Bills are frequently paid through monthly (fixed) payments with one clearance at the end of the year. It is therefore almost impossible to base one's decisions on energy consumption - thus spot the biggest energy users ${ }^{6}$.

The problem is not only lack of information, but also asymmetry in information. Sanstad and Howarth [6] call this a special case of imperfect information when "two parties have access to different levels of information". Typically this would be a case of producers versus consumers. Asymmetry in information levels is, according to the authors, a rule rather than an exception.

Schleich and Gruber [7] offer audits as a solution to the information barrier. Nonetheless, they add in the same breath that those who would make use of it are usually the ones who will also lack the resources for such an audit.

Finally, even if we suppose that the actors do receive all the needed information, another barrier seems to be a lack of knowledge or capacity to evaluate it correctly and draw correct conclusions. This is the problem of households, and also of SMEs, which typically do not have a specialized energy expert.

\subsection{Incorrect risk assessment}

Generally, using an excessively high discount rate $^{7}$ in assessing the economic effectiveness of energy saving measures is thought to be another major source of the so-called "efficiency gap" $[11,12]$. Many empirical studies have shown that customers (households and firms) discount the energy savings by tens \%, thus significantly lowering their present value (see e.g. $[11,6,13])$. Howarth and Anderson [8] estimate that the discount rates start from $20-25 \%$ but can reach up to $800 \%$, much more than the returns on other investments would be. According to Vine et al. [14], the level of the discount rate can reach up to $50 \%$. There are various reasons for this, but all of them together very often reflect the barriers discussed so far.

\footnotetext{
${ }^{3}$ However, this is by no means always true, as shown e.g. in [2] where a study on refrigerators and freezers is cited in which little correlation was found between upfront costs and energy performance. In addition, there is strong role of behavior which can be important but, of course, has a zero cost.

${ }^{4}$ This is very much related to the issue of transaction costs, which is elaborated in detail below.

${ }^{5}$ Though Reddy [2] notes that the problem of insufficient information will appear also at governmental level, related to policy making.

${ }^{6} \mathrm{~A}$ solution to this seems to lie in a transition to smart grids and smart meters. Apart from advantages for energy suppliers, it is believed that smart meters encourage energy savings through real time provision of information on energy consumption, which can also be further split down to end-uses. More on the discussion on smart meters e.g. in [10].

${ }^{7}$ It is important to keep in mind that here we are discussing the discount rate used by investors in the meaning of investors' opportunity cost, not really the interest rate that the bank will give to the investor. This is discussed in the section on access to capital.
} 
One of the main determinants influencing the risk of achieving future energy savings is seen to be the energy price. This is why e.g. Thompson [11] proposes using two different discounts, one for the old equipment and the other for the new, efficient equipment, because if the energy source is changed with the efficiency measure, then it may also be necessary to consider a different risk in energy prices for the two (old and new) installations. Another example would be the transition to a different tariff and also with the two-part price of energy changing the type of equipment can lead to a change in the fixed part of the price.

Apart from the future energy price, another determinant is energy consumption. If the energy efficiency measure is rather common or not too complex (e.g. lighting), future energy consumption can be well estimated from the technical parameters of the equipment. With more complex installations, future energy consumption can also represent a risk or an uncertainty, and thus may provide a reason for a higher discount rate. This is also related to the fact that energy-efficient equipment is often new to the market and thus investors will attach more risk to it $[8]^{8}$.

In general, both above analyzed risks or uncertainties lead to the use of a higher discount rate. Stochastic energy prices will, as Schleich and Gruber [7] note, raise the investor's required rate of investment (discount). Thompson [11] however argues that with energy saving measures, the correct method would be to actually use a lower discount rate. The reason is that the main source of uncertainty towards the future is the energy price (and energy consumption), whereas the energy efficiency measure will then lead to a "lower variation in investor wealth" [11].

Other explanation would be through the Capital Assets Pricing Model (CAPM). Using more efficient equipment and thus achieving energy savings will lead to a decrease in the systemic risk [15]. The reason is that lower incomes of the market will usually correlate with higher energy prices, which on the contrary advantages energy saving measures. In other words, energy saving measures can serve as a "safety fuse" against price volatility.

\subsection{The principal/agent problem}

The "principle-agent" problem is basically a barrier of split incentives (or of the separation of responsibilities for energy expenditures and conservation actions [1]). The owners of the facility (of the rental unit) do have the incentive to invest in the efficiency measure. However, they will have no control over the use of the efficient equipment and thus no control over the efficiency gains. Furthermore, the owner does not receive the benefits of the measure, because it is the user who pays lower energy bills.

Conversely, the user receives all the benefits from the efficiency measure, but has no incentive to invest, as there is high uncertainty as to length of the contract. It is likely that the user will not be able to benefit fully from the cost savings (will simply have to move out before all the cost savings can be realized), which makes the investment economically disadvantageous.

Schleich and Gruber [7] however point out that the barrier of split incentives is more significant for households than for private companies and for public sector, as these usually have longer rental contracts than is the case for households.

\subsection{Transaction costs in energy efficiency}

The reason why transaction costs are depicted separately is that they tend to include or stem from all the above barriers.

The level of transaction costs is not negligible, and is likely to prevent energy efficiency measures from being implemented. However, the exact size of transaction costs remains still rather unclear, partly because there is no common method for evaluating them and including them in decision making.

Most authors state that the transaction costs in energy efficiency are real and are on a significant level. They may hamper the implementation of energy efficiency projects, or may even outweigh the gains of energy efficiency improvements and thus lead to their non-realization, or to a preference for inefficient or standard technologies.

A suitable definition of transaction costs in energy efficiency seems to be provided by Matthews [16]: "... the costs of arranging a contract ex ante and monitoring and enforcing it ex post, as opposed to production costs." This can be applied both to investments in efficiency measures, and to policy instruments (in this case, the contract can be subsituted for a policy instrument).

The transaction costs are borne either by the project developers, by the programme managers or by the beneficiaries of EE programmes. The transaction costs therefore pertain to the costs related to investment, operation and maintenance, verification, and/or administrative costs. Lack of information and transaction costs are sometimes interchanged [7].

Energy efficiency transaction costs can be divided into four main stages in which transaction costs can occur: the planning phase, the implementation phase, monitoring phase and the verification phase (Table 1).

\footnotetext{
${ }^{8}$ In addition, future consumption is not dependent only on technical specifications, but to large extent also on the consumer's behavior and usage. Similarly, future energy consumption will depend on the reference scenario, i.e. the future energy consumption of existing equipment.
} 
Table 1: Sources of transaction costs. Source [17]

\begin{tabular}{|c|c|}
\hline Project phase & Nature of transaction costs \\
\hline Planning & $\begin{array}{l}\text { - Search for information } \\
\text { - Search for costumers } \\
\text { - Legal fees } \\
\text { - Development of proposal } \\
\text { (including development of } \\
\text { baseline, M\&V } \\
\text { methodologies, etc.) } \\
\text { - Project identification and } \\
\text { evaluation }\end{array}$ \\
\hline Implementation & $\begin{array}{l}\text { - Megotiation of contracts } \\
\text { - Procurement } \\
\text { - Project validation }\end{array}$ \\
\hline $\begin{array}{l}\text { Monitoring and } \\
\text { verification }\end{array}$ & $\begin{array}{l}\text { Mechanisms to monitor, } \\
\text { quantify and verify savings } \\
\text { and related GHG } \\
\text { emissions reductions } \\
\text { (including installation of } \\
\text { required equipment) }\end{array}$ \\
\hline
\end{tabular}

The planning phase mostly consists of searching for information, project identification, evaluation and proposal. In the implementation phase, the negotiation process is important. The last phase basically means monitoring and verifying the energy savings and/or GHG emissions reductions. Björkqvist and Wene [18] also emphasize the importance of including the potential active rejection in the calculation. Active rejection means that the actors actually considered the option and actively rejected it. Those actors also incur transaction costs.

General knowledge about the negative impact of transaction has been supported by a number of studies (eg. in $[19,20,2,6])$. However, empirical data is still lacking. The reasons for this include the fact that the actors are often reluctant to disclose information. Also, there is a lack of ex-post evaluations, which serve as an important source for estimates of transac- tion costs. In addition, transaction costs are relatively case specific [21].

Some of the small number of studies that evaluate the level of transaction costs of different programmes are presented here. It is important to keep in mind though, that because different methods and sectors are being analyzed, the studies are not directly comparable.

Björkqvist and Wene [18] udnertook a study of transaction costs in families that participated in a demand side management (DSM) programme in Göteborg. They analyzed 51 families who decided to invest in upgrading their heating systems. The transaction costs were not measured in monetary terms, but in hours spent by the families. The authors found that on an average the families spent 18 hours on the decision making process. They also assessed the time spent by non-investors (active rejection), which was only 6 hours. Importantly, a lot of information was provided by the energy supplier, who was the initiator of the DSM programme (e.g. the potential suppliers of energy efficiency equipment, information on options, etc). In this way, some time for information searching was definitely saved. The authors transposed the hours into monetary terms, using labor costs as a proxy. The transaction costs then represented $\mathbf{2 8} \%$ of the average investment if gross income was taken, or $13 \%$ if net income was used. The authors admit that the numbers may be underestimated because, firstly, the households may not have remembered every minute of the time they spent on the decision and, secondly, because part of the decision stage was not included as it was provided by the distribution company.

Michaelowa and Jotzo [22] evaluated the transaction costs of several GHG emissions schemes, namely the AIJ in Sweden (the predecessor of the Joint Implementation Mechanism) and the CDM. The main sources of transaction costs under these schemes are the search costs, baseline development, approval costs (to have the $\mathrm{CO}_{2}$ emission reduction approved by the approving authority), validation, registration and monitoring. The main findings are that there is a significant fixed part in the transaction cost in the GHG

Table 2: Empirical estimates of transaction costs. Compiled by author

\begin{tabular}{|l|r|l|l|}
\hline Study & Level of TCs & Field & Note \\
\hline Björkqvist et al. [18] & $28 \%(13 \%)$ & Households & If gross (net) income referred to \\
\hline Michaelowa and Jotzo [22] & $20.5 \%$ & CDM & \\
\hline Mundaca [21] & $10-20 \%$ & Audit scheme & $\%$ of the audit costs \\
\hline Mundaca [21] & $8-12 \%$ & Lighting & Energy saving target programme \\
\hline Mundaca [21] & $24-36 \%$ & Insulation & Energy saving target programme \\
\hline Sathaye [23] & $20-19 \%$ & Not specified & \\
\hline Easton Consultants $[24]$ & 20 & ESCOs & \\
\hline
\end{tabular}


schemes. This means that there is a certain threshold of $\mathrm{CO}_{2}$ savings below which the transaction costs outweigh the gains of the project. One study finds this threshold at a level of 50000 t $\mathrm{CO}_{2} / \mathrm{yr}$ for a 20-year project; another value is that the transaction costs should not be more than $25 \%$ of the proceeds from permit sales in order to make a project viable [22]. Overall, the level of transaction costs was estimated at ca $\mathbf{2 0 . 5} \%$ of total project costs.

Mundaca [21] analyzed two energy efficiency programmes: free of charge energy audits in Denmark, and the energy efficiency commitment in Great Britain. The results of the former cannot really be considered as statistically relevant, as they were based only on 5 replies. Nevertheless, a qualitative analysis was made. The idea is that the energy providers have to make some number of energy audits of their customers. The rationale behind the programme is that the market agents have asymmetric information and thus they will not materialize all the energy improvements. The transaction costs are related mainly to finding clients for the audit as such, carrying out the audit, and also to follow up measures, such as the search for partners if the client decides to implement some measures. Another source of TCs is the accreditation process, as the energy audit has to be reported as part of the programme. The transaction costs were estimated as 10-20 \% of the direct costs of the energy audit (not the costs of potential resulting investment).

The British programme sets an energy saving target to be fulfilled by energy supply companies. The companies can trade the savings among themselves. The author [21] interviewed suppliers and asked them to identify and quantify the transaction costs related to the programme. The identified transaction costs were mainly searches for information (searches for households that could save), persuading customers or approval of measures by the authority. In the implementation phase the main source of TC was in negotiating agreements or contracts with a third party and in monitoring and verification. Random quality checks were the main source. All together, the level of TC differed according to the measure undertaken. In lighting, the transaction costs ranged from $8 \%$ to $12 \%$, and with insulation measures the range was 24-36 \% of the investment costs.

Sathaye [23] analysed various emission reduction projects (not only energy efficiency) in North and South America and Asia, and estimated that the transaction costs ranged from $9 \%$ to $19 \%$ of total project costs. The transaction costs arise mainly from the negotiation process among parties, feasibility studies (including baselines and additionality), negotiation, monitoring and evaluation and also approval from the managing authority. Sathaye also believes that the key factor determining the level of transaction costs (at least in GHG projects) is project size.
A few studies have focused on the transaction costs borne by Energy Service Companies (ESCOs). Easton Consultants [24] estimated that the transaction costs of energy efficiciency projects carried out by ESCOs represented from $20 \%$ to $\mathbf{4 0} \%$ of the total value of the project (Figure 1).

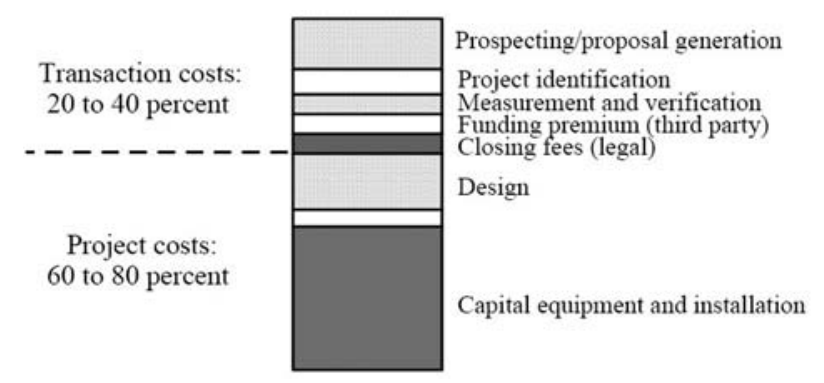

Fig. 1: Costs associated with the ESCO project. Source [24]

\section{$3 \quad$ Policy implications}

Various policy instruments are needed to help removing the different barriers to energy efficiency. The instruments range from providing a regulatory framework, which should allow the market to develop, through hard regulatory instruments (minimum efficiency standards, building codes), financial incentives (subsidies, loans) to soft (information) measures. There is no silver bullet, but a set of instruments has to be put in place.

From practice, the barrier of lack of information has been dealt with using various policy instruments. On the EU level, depending on the sector or the enduse, hard regulations or labelling have been adopted. The former (in the form of minimum efficiency standards) passes the difficulty and costs that the consumers incur while searching for information on the producers. If minimum efficiency standards (MEPS) are adopted, consumers are sure to buy efficient products instead of having to look for them. This is the case for example for standby regulation, where the search for information at each individual appliance would be too costly.

The labelling approach is an example of a successful soft, information measure, which has helped in achieving energy efficiency at low costs. It has been the most effective in the case of appliances that represent a significnat portion of a household budget (e.g. refrigerators or washing machines). Conversely, the labelling has not worked for lighting, though the savings and the related economic effectiveness are unquestionnable.

In addition, in one of the above-mentioned case studies, the lack of information (and thus high transaction costs in the initial planning phase) was solved 
by passing the burden to a distribution company. The information was gathered and pooled at a single place and then distributed to the households, which reduced the transaction costs for the families and increased the effectiveness of the actions [18].

In some cases, it is sufficient to set up the right regulatory framework. That is the case for e.g. the principal/agent dilemma. Schleich and Gruber [7] suggest that this barrier could be avoided if "the investing party were able to credibly transmit the information about the benefits (i.e., future cost savings) arising from the investment, and to enter into a contract with those benefiting from the investment". One can imagine a policy instrument that will help in establishing the environment for such information transfer (by e.g. providing standard documents for both parties).

As to risk management, a solution offered e.g. by Mills [25] is to use insurance in energy saving projects. Another way is to use real options, well developed in other sectors, but not yet in energy saving projects. Some authors also imply that incorrect risk assessment is only a result of the other barriers. Therefore, removing this barrier will depend on removing the other barriers.

\subsection{Transaction cost policy implications}

The stakeholders are usually aware of the existence of transaction costs in energy efficiency projects and programmes, but know neither their structure nor the exact levels. Therefore, a common method is needed for including them in decision making, both at the level of the investor and also at the level of the policy makers. This will also allow a direct comparison, which is not possible at the moment.

From the case studies mentioned above, some preliminary ideas for the development of such a method are drawn. Firstly, there is an indirect relation between the size of the project and the transaction costs, which thus justifies streamlining. In other words, bundling and standardizing projects could reduce the fixed part of the transaction costs, which tends to be an inhibitor of efficiency measures in smaller projects (SMEs, households, and others). Economies of scale play an important role in programmes, where the fixed part of the transaction costs is significant [22].

The need to assess the transaction costs with respect to time is also stressed, as there may be a learning curve in (at least some forms of) transaction costs, depending on the general context of the programme [22].

It seems that the transaction costs tend to vary from sector to sector. In the household sector, the transaction costs are higher than in the commercial sector and the industry. The reason probably relates to the importance of project size. The commercial and industrial sector will also more likely benefit from economies of scale and from fewer market imperfections.

Providing a framework for developing the energy service $^{9}$ market may be a useful supplementary tool. The ESCO, from the very nature of the business, has an interest in including all the costs in their calculations [19], thus also all the transaction and more generally hidden costs. Energy efficiency services can solve the problem of limited access to capital, as one of the potential services is to offer repayment of the loan from guaranteed savings, thus removing the financial risk to the client.

\section{Acknowledgement}

Research described in the paper was supervised by doc. Ing. Jaroslav Knápek, CSc., FEE CTU in Prague.

\section{References}

[1] Jochem, E., Gruber, E.: Obstacles to rational electricity use and measures to alleviate them. Energy Policy, 1990, vol. 18, no. 4, p. 340-350.

[2] Reddy, A. K. N.: Barriers to improvements in energy efficiency. Energy Policy, December 1991, p. 953-996.

[3] Birol, F., Keppler, J. H.: Prices, technology development and the rebound effect. Energy Policy, 2000, vol. 28, p. 457-469.

[4] World Energy Council: Energy Efficiency Policies around the World: Review and Evaluation. London : World Energy Council, 2008.

[5] Sorrell, S. Dimitropoulos, J., Sommerville, M.: Empirical estimates of the direct rebound effect: A review. Energy Policy, Vol. 37, No. 4, 2009, p. $1356-1371$.

[6] Sanstad, A. H., Howarth, R. B.: "Normal" markets, market imperfections and energy efficiency. Energy Policy, 1994, Vol. 22, No. 10, p. 811-818.

[7] Schleich, J., Gruber, E.: Beyond case studies: Barriers to energy efficiency in commerce and the services sector. Energy Economics, 2008, Vol. 30, p. 449-464.

[8] Howarth, R. B., Anderson, B.: Market barriers to energy efficiency. Energy Economics, October 1993, p. 262-272.

\footnotetext{
${ }^{9}$ Defined in the Energy service directive (2006/32/EC) as "the physical benefit, utility or good derived from a combination of energy with energy efficient technology and/or with action, which may include the operations, maintenance and control necessary to deliver the service, which is delivered on the basis of a contract and in normal circumstances has proven to lead to verifiable and measurable or estimable energy efficiency improvement and/or primary energy savings."
} 
[9] Darby, S.: Implementing Article 13 of the Energy Services Directive and defining the purpose of new metering infrastructures. In Proceedings of ECEEE 2009 Summer Study. Act! Innovate! Deliver! Reducing energy demand sustainably. Edited by Broussous, C., Jover, C. ECEEE: Stockholm, 2009, p. 441-452.

[10] Darby, S.: The Effectiveness of Feedback on Energy Consumption. A Review for Defra of the Literature on Metering, Billing and Direct Displays, 2006, Available from

http://www.eci.ox.ac.uk/research/energy/

downloads/smart-metering-report.pdf

(Accessed February 2010).

[11] Thompson, P. B.: Evaluating energy efficiency investments: accounting for risk in the discounting process. Energy Policy, 1997, Vol. 25, No. 12, p. $989-996$.

[12] Koopmanss, C. C., Willem Te Velde, D.: Bridging the energy efficiency gap: using bottom-up information in a top-down energy demand model. Energy Economics, Vol. 23, No. 1, January 2001, p. $57-75$.

[13] Oikonomou, V., Rietbergenb, M., Patelbet, M.: An ex-ante evaluation of a White Certificates scheme in The Netherlands: A case study for the household sector. Energy Policy, 2007, Vol. 35, p. 1147-1 163.

[14] Vine, E., Kats, G., Sathaye, J., Joshi, H.: International greenhouse gas trading programs: a discussion of measurement and accounting issues. Energy Policy, Vol. 31, No. 3, 2003, p. 211-224.

[15] Stoft, S.: Appliance standards and the welfare of poor families. The Energy Journal, Vol. 14, No. 4, 1993 , p. $123-128$.

[16] Matthews, R. C. O.: The economics of institutions and the sources of growth. The Economic Journal, 1986, Vol. 96, No. 384, p. 903-918.

[17] Mundaca, L., Neij, L.: Transaction costs of energy efficiency projects: A review of quantitative estimations. Report prepared under Work Package 3 of the EuroWhiteCert project, 2006.

[18] Björkqvist, O., Wene, C.: A study of transaction costs for energy investments in the residential sector. In Proceedings of the 1993 Summer Study. The European Council for an Energy Efficient Economy (ECEEE), Stockholm, 1993, p. 23-30.

[19] Ostertag, K.: Transaction costs of raising energy efficiency. International workshop on technologies to reduce greenhouse gas emissions: Engineeringeconomic analyses of conserved energy carbon.
Washington D.C., USA, 1999. Available from http://www.isi.fhg.de/publ/downloads/isi99a19/ energyeffiency.pdf (Accessed February 2010).

[20] Ostertag, K.: No-regret Potentials In Energy Conservation: An Analysis Of Their Relevance, Size And Determinants, Springer Berlin : Heidelberg, 2003.

[21] Mundaca, L.: Transaction costs of energy efficiency policy instruments. In Proceedings of the ECEEE 2007 SUMMER STUDY - SAVING ENERGY - JUST DO IT!, edited by Attali, S. and Tillerson, K., ECEEE: Stockholm, 2007, p. $281-291$.

[22] Michaelowa, A., Jotzo, F.: Transaction costs, institutional rigidities and the size of the clean development mechanism. Energy Policy, 2005, Vol. 33, p. 511-523.

[23] Sathaye, J. A.: Expediting energy efficiency project methodologies. Bonn, Germany, Lawrence Berkeley National Laboratory, 2005. Available from

http://www.meti.go.jp/policy/global_environment/ kyomecha/050531FutureCDM/Committee/

Sathaye-May\%2020-Methodologies-Future \% 20CDM-Japan.pdf (Accessed February 2010).

[24] Easton Consultants, S. F. M. C.: Energy Service Companies. A Market Research Study, Prepared for Energy Center of Winsconsin: 64, 1999. Available from http://www.ecw.org/ecwresults/181-1.pdf (accessed February 2010).

[25] Mills, E.: Risk transfer via energy-savings insurance. Energy Policy, Vol. 31, No. 3, 2003, p. $273-281$.

\section{About the author}

Michaela VALENTOVÁ, MSc. was born in Prague. She graduated from Central European University in Budapest and is currently a $\mathrm{PhD}$ student at the Faculty of Electrical Engineering, Czech Technical University in Prague. Her major area of research is barriers to energy efficiency and evaluation of energy efficiency policy instruments and their economic effectiveness.

Michaela Valentová

E-mail: valenmi7@fel.cvut.cz

Dept. of Economics, Management and Humanities

Faculty of Electrical Engineering

Czech Technical University

Technická 2, 16627 Praha, Czech Republic 